\title{
Mengkaji Hasil Evaluasi Calon Pendidik Matematika pada Keterampilan Mengajar dalam Micro Teaching
}

\author{
Lutfiyah $^{1)}$, Eric Dwi Putra ${ }^{2)}$ \\ ${ }^{1,2)}$ IKIP PGRI Jember \\ Email: azkalutfimh@gmail.com,dwieric454@gmail.com
}

\begin{abstract}
Micro Teaching helps prospective educators to prepare themselves before carrying out practical field experiences, the basis of self-readiness in facing the future as a professional teacher. The purpose of the study was to find out in detail the low percentage of achievements found in 4 indicators from the evaluation results of prospective mathematics educators on teaching skills in micro-teaching. This type of research is descriptive qualitative, data collection is done through tests, observation, documentation. The data analysis used is based on the Miles and Huberman model, the activities carried out through data reduction, data display, and conclusion. The results showed that the four indicators of teaching skills were: 1 . Strengthening in the form of simbols, 2. Assisting, 3. Analyzing student views, 4. Organizing, M1 in evaluation I and evaluation II did not do the four indicators, while M2 did not do indicators 1 and 2 while indicators 3 and 4 are carried out but not at every evaluation. The conclusion from the evaluation results of prospective mathematics educators on the teaching skills of the four indicators with low percentage achievements during the practice of micro-teaching was due to negligence in conveying indicators of teaching skills, not due to the lack of understanding of the practitioners of each indicator.
\end{abstract}

Keywords : Evaluation Results, Teaching Skills, Micro Teaching

\begin{abstract}
ABSTRAK
Micro Teaching membantu calon pendidik untuk menyiapkan diri sebelum melaksanakan praktek pengalaman lapangan, selain itu merupakan dasar kesiapan diri dalam menyongsong masa depan sebagai guru yang professional. Tujuan dari penelitian, untuk mengetahui secara detail capaian persentase rendah yang terdapat pada 4 indikator dari hasil evaluasi calon pendidik matematika pada keterampilan mengajar dalam Micro Teaching. Jenis penelitian ini deskriprtif kualitatif, Pengumpulan data dilakukan dengan cara tes, observasi, dokumentasi. Analisa data yang digunakan berdasarkan model Miles and Huberman, aktivitas yang dilakukan dengan cara reduksi data, display data dan Kesimpulan. Hasil penelitian bahwa keempat indikator keterampilan mengajar yaitu: 1. Penguatan berupa simbol, 2.
\end{abstract}


Pemberian bantuan, 3. Menganalisis pandangan siswa, 4. Mengorganisasi, M1 dalam evaluasi I dan evaluasi II tidak melakukan keempat indikator tersebut, sedangkan M2 tidak melakukan indikator 1 dan 2 sedangkan indikator 3 dan 4 dilakukan tetapi tidak pada setiap evaluasi. Kesimpulan dari hasil evaluasi calon pendidik matematika pada keterampilan mengajar dari keempat indikator dengan capaian persentase rendah saat praktek Micro Teaching, diakibatkan kelalaian dalam menyampaikan indikator keterampilan mengajar, bukan disebabkan ketidakpahaman praktikan terhadap masing-masing indikator.

Kata Kunci : Hasil Evaluasi, Keterampilan Mengajar, Micro Teaching

\section{PENDAHULUAN}

Tugas utama seorang guru adalah mengajar (Mulyasa, 2008). Menjadi seorang guru harus memiliki keterampilan dasar, tanpa adanya keterampilan dasar dalam mengimplementasikan kurikulum seideal apapun tidak akan maksimal, seorang guru tidak dilahirkan melainkan harus dibentuk terlebih dahulu, agar guru memiliki performance yang baik, maka diperlukan keterampilan dasar dalam mengajar (Mansyur, 2017). Dalam membentuk performance seorang guru, terletak pada mata kuliah micro teaching yang berada pada semester 6 pada jenjang strata 1, Asral mengatakan bahwa untuk meningkatkan kemampuan calon guru dalam mengajar perlu mengembangkan pembelajaran micro (Handhika J, 2016). Micro Teaching atau simulasi mengajar merupakan suatu kegiatan pembelajaran mahasiswa dengan cara berkelompok pada ruang atau laboratorium Micro Teaching untuk mengembangkan keterampilan dan kemampuan mahasiswa dalam melaksanakan kegiatan praktek mengajar sebelum menghadapi program pengalaman lapangan, dimana mahasiswa diminta praktek mengajar terjun langsung pada sekolah atau siswa (Ardi M, 2014)

Micro Teaching merupakan langkah awal untuk mencetak seorang pendidik, Micro Teaching merupakan mata kuliah untuk melatih mahasiswa menjadi seorang pendidikan yang professional, kompetensi professional diartikan kemampuan khusus seorang guru berkaitan dengan pelaksanaan tugasnya (Aryulina D, 2010). Micro Teaching berada pada jenjang strata 1 semester 6, mata kuliah Micro Teaching membantu calon pendidik untuk menyiapkan diri sebelum melaksanakan praktek pengalaman lapangan, selain itu merupakan dasar kesiapan diri dalam menyongsong masa depan sebagai guru yang professional setelah lulus nantinya. Dalam mata kuliah Micro Teaching ada 8 keterampilan mengajar yang harus dikuasi oleh mahasiswa 
diantaranya 1). keterampilan membuka dan menutup pelajaran, 2). keterampilan menjelaskan, 3). keterampilan reinforcement, 4). keterampilan memberi variasi stimuli, 5). keterampilan mengelola kelas, 6). keterampilan bertanya, 7). keterampilan memimpin diskusi kelompok kecil, 8). keterampilan mengajar kelompok kecil/perorarngan.

Berdasarkan analisa dari hasil penelitian sebelumnya dengan judul "evaluasi praktik Micro Teaching mahasiswa berdasarkan instrumen UPT-PPL" bahwa hasil rata-rata dari 8 keterampilam mengajar dalam kategori cukup yaitu keterampilan mengajar nomor 1, kategori baik yaitu nomor 3, 7, 8 sedangkan kategori sangat baik yaitu nomor 2, 4, 5, 6. Terlihat pada tabel di bawah.

Tabel 1. Kategori Pencapain Evaluasi Micro Teaching

\begin{tabular}{cccc} 
No. & $\begin{array}{c}\text { Capaian Evaluasi } \\
\text { Praktik }(\%)\end{array}$ & $\begin{array}{c}\text { Keterampilan } \\
\text { Mengajar }\end{array}$ & Kategori \\
\hline 1. & 63.5 & 1 & Cukup \\
2. & $73.1-77.1$ & $3,7,8$ & Baik \\
3. & $81.3-100$ & $2,4,5,6$ & Sangat Baik \\
\hline
\end{tabular}

Berdasarkan tabel kategori pencapaian hasil evaluasi Micro Teaching pada penelitian sebelumnya, maka pada artikel ini akan mengkaji secara detail 4 indikator capaian dengan persentase $<50 \%$ (persentase rendah) dari 35 indikator yang tersebar dalam 8 keterampilan mengajar. Sebanyak 1 indikator dengan capaian persentase rendah pada keterampilan membuka pelajaran sudah dikaji pada artikel sebelumnya dengan judul "Micro Teaching Mahasiswa Calon Pendidik IKIP PGRI Jember: Apersepsi untuk Pembelajaran Matematika". Sedangkan 4 indikator capaian persentase rendah yang lainnya terlihat pada tabel di bawah.

Tabel 2. Capaian Persentase Rendah

\begin{tabular}{clcc}
\hline No. & \multicolumn{1}{c}{ Keterampilan Mengajar } & Ev. I (\%) & Ev.II (\%) \\
\hline 1 & $\begin{array}{l}\text { KETERAMPILAN REINFORCEMENT/PENGUATAN } \\
\text { Penguatan berupa simbol }\end{array}$ & 44.4 & 44.4 \\
2 & $\begin{array}{l}\text { KETERAMPILAN BERTANYA } \\
\text { Pemberian bantuan }\end{array}$ & 38.9 & 38.9 \\
3 & $\begin{array}{l}\text { KETERAMPILAN MEMIMPIN DISKUSI KELOMPOK } \\
\text { Menganalisis pandangan siswa }\end{array}$ & 16.7 & 22.2
\end{tabular}


Volume 3, Nomor 2, Oktober 2020

4 KETERAMPILAN MENGAJAR KELOMPOK

KECIL/PERORANGAN

38.9

33.3

Mengorganisasi

Tujuan dari penelitian, untuk mengetahui secara detail capaian persentase rendah yang terdapat pada 4 indikator dari hasil evaluasi calon pendidik matematika pada keterampilan mengajar dalam Micro Teaching. Menurut Suyanto \& Jihad A. evaluasi individu adalah prestasi yang dicapai dalam belajar baik kelompok atau kelas, dengan evaluasi akan mendapatkan informasi tentang apa yang dicapai dan bagian mana yang belum dicapai, informasi yang diperoleh untuk meningkatkan dan memperbaiki suatu program (2013).

Jenis penelitian ini deskriprtif kualitatif dengan subjek penelitian mahasiswa semester 6 yang menempuh mata kuliah Micro Teaching dengan sample sebanyak 2 mahasiswa/praktikan diambil secara acak (disebut M1 \& M2) yang memiliki nilai ratarata rendah dari hasil evaluasi I dan evaluasi II, Instrument penelitian antara lain lembar penilaian observer, lembar penilaian dosen pembimbing, catatan lapang. Pengumpulan data dilakukan dengan cara tes, observasi, dokumentasi, Analisa data yang digunakan berdasarkan model Miles and Huberman dimana analisa data dilakukan selama pengumpulan data sedang berlangsung dan ketika setelah selesai pengumpulan data dalam suatu periode tertentu (Sugiyono, 2014). Aktivitas yang dilakukan dengan cara sebagai berikut, yaitu: 1. reduksi data, 2. display data dan 3 . Kesimpulan.

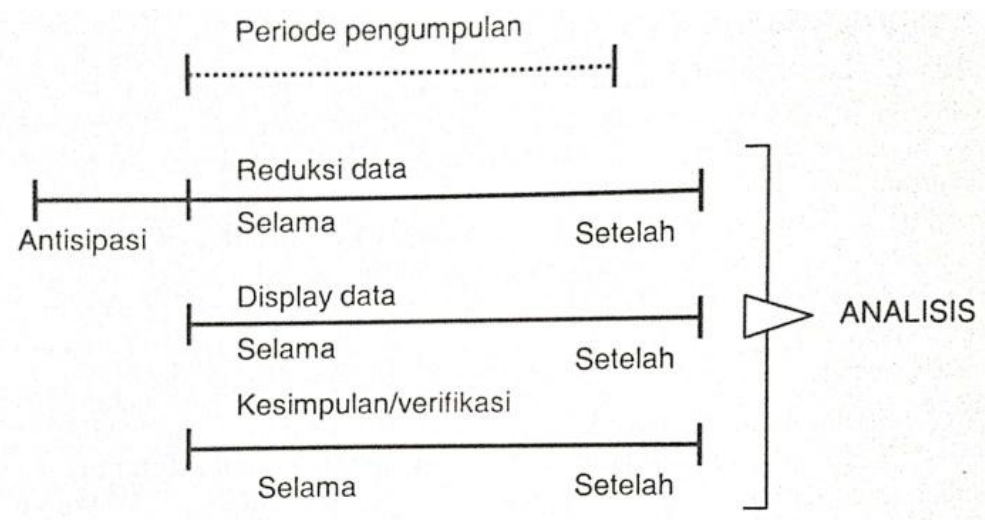

Gambar 1. Analisa data Flow Model (Sugiyono, 2014) 


\section{HASIL DAN PEMBAHASAN}

Pemberian evaluasi dilakukan setelah masing-masing mahasiswa melakukan praktek mengajar sebanyak 1 kali, setiap selesai praktek mengajar selalu diikuti evaluasi, dalam penelitian ini diambil data evaluasi sebanyak 2 kali, hasil evaluasi dari penilaian dosen pembimbing dan penilaian observer, setiap selesai evaluasi I dosen pembimbing selalu menyampaikan kekurangan yang dimiliki setiap mahasiswa agar masing-masing mahasiswa mengetahui bagian-bagian dari indikator keterampilan mengajar yang perlu diperbaiki apabila kurang tepat atau perlu dilakukan jika terlupakan penyampaian.

Hasil evaluasi I dan evaluasi II oleh M1 saat Micro Teaching dengan materi Aljabar terlihat pada tabel di bawah

Tabel 3. Hasil Evaluasi M1

\begin{tabular}{clcc}
\hline No. & \multicolumn{1}{c}{ Keterampilan Mengajar } & Ev. I & Ev.II \\
\hline 1 & KETERAMPILAN REINFORCEMENT/PENGUATAN & & \\
& Penguatan berupa simbol & - & \\
2 & KETERAMPILAN BERTANYA & - & - \\
& Pemberian bantuan & & \\
3 & KETERAMPILAN MEMIMPIN DISKUSI KELOMPOK & - \\
& Menganalisis pandangan siswa & & \\
4 & KETERAMPILAN MENGAJAR KELOMPOK & - & - \\
& KECIL/PERORANGAN & & \\
Mengorganisasi & &
\end{tabular}

Dari hasil evaluasi M1 terlihat pada tabel di atas bahwa tidak terdapat tanda ceklist pada kedua evaluasi, artinya M1 tidak melakukan keempat indikator tersebut, keterampilan mengajar dalam memberi keterampilan reinforcement pada indikator penguatan berupa simbol tidak dilakukan oleh M1, sedangkan keterampilan bertanya pada indikator pemberian bantuan M1 bukan memberikan bantuan pada siswa melainkan langsung memberikan jawabannya saat menyelesaikan masalah yang diberikan. Keterampilan memimpin diskusi kelompok pada indikator menganalisa pandangan siswa, M1 tidak menganalisa hasil diskusi siswa sehingga dari hasil diskusi seperti tidak ada ujungnya, penugasan yang diberikan pada siswa oleh M1 saat diskusi hanya dikerjakan oleh 1 kelompok didepan kelas lalu untuk kelompok yang lain hanya dikumpulkan, dari hasil pekerjaan kelompok 2 hanya dicocokkan oleh jawabannya 
sendiri, untuk keterampilan mengajar kelompok kecil pada indikator mengorganisasi dimana M1 kurang kesiapan diri untuk melakukan praktek Micro Teaching sehingga terjadi sedikit kegaduhan saat pembelajaran disebabkan karena M1 kurang memahami materi yang akan disampaikan, sesekali masih sibuk dengan melihat buku materi yang akan disampaikan pada siswa.

Sedangkan hasil evaluasi I dan evaluasi II oleh M2 saat Micro Teaching dengan materi Statistika terlihat pada tabel di bawah

Tabel 4. Hasil Evaluasi M2

\begin{tabular}{clcc}
\hline No. & \multicolumn{1}{c}{ Keterampilan Mengajar } & Ev. I & Ev.II \\
\hline 1 & KETERAMPILAN REINFORCEMENT/PENGUATAN & & \\
& Penguatan berupa simbol & - & \\
2 & KETERAMPILAN BERTANYA & - & - \\
& Pemberian bantuan & & \\
3 & KETERAMPILAN MEMIMPIN DISKUSI KELOMPOK & - & $\sqrt{ }$ \\
& Menganalisis pandangan siswa & & \\
& KETERAMPILAN MENGAJAR KELOMPOK & & \\
& $\begin{array}{l}\text { KECIL/PERORANGAN } \\
\text { Mengorganisasi }\end{array}$ & $\sqrt{ }$ \\
\hline
\end{tabular}

Dari hasil evaluasi M2 pada tabel diatas terdapat tanda ceklist dari kedua hasil evaluasi, keterampilan mengajar dalam memberi reinforcement pada indikator penguatan berupa simbol tidak dilakukan oleh M2, sedangkan keterampilan bertanya pada indikator pemberian bantuan yang seharusnya dilakukan oleh M2 pada setiap kelompok yang membutuhkan apabila terjadi kesulitan dalam menyelesaiakan masalah yang diberikan, tetapi M2 bukan memberikan bantuan tetapi langsung membisikkan jawabannya pada kelompok yang sedang ditunjuk untuk maju, tetapi tidak bisa menyelesaikan. Keterampilan memimpin diskusi kelompok pada indikator menganalisa pandangan siswa pada evaluasi I tidak dilakukan oleh M2 tetapi pada evaluasi II dilakukan, karena M2 mengingat hasil evaluasi dari dosen pembimbing atas kekurangan atau beberapa hal yang harus diperbaiki saat melakukan evaluasi II, untuk keterampilan mengajar kelompok kecil pada indikator mengorganisasi kelas pada evaluasi I terlaksana dengan baik, tetapi pada evaluasi II M2 malah tidak bisa mengorganisir kelompok kecil dengan baik, dimana siswa hanya diminta mengerjakan media yang dipersiapkan didepan kelas untuk dikerjakan secara kelompok, M2 terlalu fokus pada media yang telah dibuatnya, selain itu penggunaan media dalam menyelesaiakn masalah yang diberikan tidak mewakili semua kelompok yang ada, sebab media yang dibuat oleh M2 dalam 
praktek Micro Teaching hanya 1 buah, akhirnya siswa yang lain hanya bengong dan tidak beraktifitas.

Dari hasil penelitian, keempat indikator keterampilan mengajar yaitu : 1. Penguatan berupa simbol, 2. Pemberian bantuan, 3. Menganalisis pandangan siswa, 4. Mengorganisasi, dimana M1 dalam evaluasi I dan evaluasi II tidak melakukan keempat indikator tersebut, sedangkan M2 pada kedua evaluasi tidak melakukan indikator 1 dan 2 sedangkan indikator 3 dan 4 dilakukan tetapi tidak pada setiap evaluasi. Pada evaluasi I dan evaluasi II terdapat persentase naik maupun turun dari masing-masing indikator keterampilan mengajar, oleh sebab itu pelaksanaan praktek Micro Teaching sebelum evaluasi harus ditambah, agar tidak terjadi grogi dari praktikan saat berada didepan kelas, sehingga mengakibatkan beberapa hal terlupakan saat pembelajaran. Evaluasi II dilakukan guna untuk memperbaiki proses pembelajaran sebelumnya, dalam pembelajaran Micro Teaching dibutuhkan keterampilan dosen pembimbing dalam menganalisis dan mengobservasi proses pembelajaran serta trampil dalam menggunakan alat evaluasi, juga mampu menjelaskan berbagai macam keterampilan yang dibutuhkan dalam proses pembelajaran (Asril Z, 2013).

\section{KESIMPULAN DAN SARAN}

Kesimpulan dari hasil evaluasi calon pendidik matematika pada keterampilan mengajar dari keempat indikator dengan capaian persentase rendah saat praktek Micro Teaching, diakibatkan kelalaian dalam menyampaikan indikator keterampilan mengajar, bukan disebabkan ketidakpahaman praktikan terhadap masing-masing indikator. Sarannya perlu diperbanyak praktek sebelum dievaluasi agar praktikan terbiasa berbicara di depan kelas.

\section{REFERENSI}

Ardi M. 2014. Pelaksanaan Pembelajaran Micro Teaching Bagi Mahasiswa Program Studi PPKn STKIP-PGRI Pontianak. Jurnal Edukasi. 1(1). 75-84

Aryulina D. 2010. Penerapan Lesson Study Pada Microteaching Bagi Calon Guru Biologi. Jurnal Forum Pendidikan. 30(1). 14-19

Asril Z. 2013. Micro Teaching Disertai Dengan Pedoman Pengalaman Lapangan. Jakarta : PT RajaGrafindo Persada 
Volume 3, Nomor 2, Oktober 2020

Handhika J. 2016. Dampak Pelaksanaan Pengajaran Mikro Beorientasi Pada Penguasaan Materi Terhadap Kualitas Mengajar MahasiswaPPL. Jurnal JPFK. 2(2). 78-83

Mansyur. 2017. Keterampilan Dasar Mengajar dan Penguasaan Kompetensi Guru. Jurnal El-Ghiroh. 7(1). 131-146

Mulyasa. 2008. Menjadi Guru Profesional Menciptakan Pembelajaran Kreatif dan Menyenangkan. Bandung : PT Remaja Rosdakarya

Sugiyono. 2014. Metode Penelitian Kuantitatif Kualitatif dan R\&D. Bandung : Alfabeta

Suyanto \& Jihad A. 2013. Menjadi Guru Profesional Strategi Meningkatkan Kualifikasi dan Kualitas Guru di Era Global. Jakarta : Erlangga 